\title{
Extrapulmonary Nontuberculous Mycobacteria Infections in Hospitalized Patients, United States, 2009-2014
}

\author{
Emily E. Ricotta, Jennifer Adjemian, ${ }^{1}$ Rebekah A. Blakney, Yi Ling Lai, Sameer S. Kadri, D. Rebecca Prevots
}

Nontuberculous mycobacteria (NTM) cause pulmonary and extrapulmonary infections in susceptible persons. To characterize the epidemiology of skin and soft tissue (SST) and disseminated extrapulmonary infections caused by NTM in the United States, we used a large electronic health record database to examine clinical, demographic, and laboratory data for hospitalized patients with NTM isolated from extrapulmonary sources during 2009-2014. Using all unique inpatients as the denominator, we estimated prevalence and summarized cases by key characteristics. Of 9,196,147 inpatients, 831 had confirmed extrapulmonary NTM. The 6-year prevalence was 11 cases $/ 100,000$ inpatients; sourcespecific prevalence was 4.4 SST infections $/ 100,000$ inpatients and 3.7 disseminated infections $/ 100,000$ inpatients. NTM species varied across geographic region; rapidly growing NTM were most prevalent in southern states. Infection with Mycobacterium avium complex was more common among patients with concurrent HIV and fungal infection, a relevant finding because treatment is more effective for $M$. avium complex than for other NTM infections.

$\mathrm{N}$ ontuberculous mycobacteria (NTM) are opportunistic bacteria that are abundant in soil and water, including natural and plumbing-associated water sources $(1,2)$. For a minority of susceptible persons, exposure to NTM can result in extrapulmonary infections (3), including skin, joint, lymph node, and disseminated infections. Extrapulmonary infections, especially disseminated disease, typically occur among persons with congenital or acquired

Author affiliations: National Institutes of Health National Institute of Allergy and Infectious Diseases, Bethesda, Maryland, USA

(E.E. Ricotta, J. Adjemian, R.A. Blakney, Y.L. Lai, D.R. Prevots);

US Public Health Service Commissioned Corps, Rockville,

Maryland, USA (J. Adjemian); National Institutes of Health Clinical

Center, Bethesda (S.S. Kadri)

DOI: https://doi.org/10.3201/eid2703.201087 immunodeficiencies (e.g., HIV infection) (4) but can also be associated with medical or cosmetic procedures that expose a wound to sources contaminated with mycobacteria $(5,6)$. A recently described outbreak identified disseminated infections with $\mathrm{Myco-}$ bacterium chimaera after open heart surgery, arising from contamination of heater-cooler units (6).

Few studies describe the epidemiology of extrapulmonary NTM in the United States at the national level. One recent study in Oregon evaluated the prevalence of extrapulmonary NTM by using statewide population-based laboratory surveillance data for 2007-2012, which included data for pulmonary and extrapulmonary NTM (4). The researchers estimated a stable annual incidence of extrapulmonary NTM infection of 1.5 cases/100,000 population. The average age of extrapulmonary NTM patients (median 51 years) was younger than that of pulmonary NTM patients. In addition, rapidly growing NTM species were identified at a much greater frequency in extrapulmonary than in pulmonary NTM patients and represented one third of all cases in Oregon (4). Epidemiologic studies of pulmonary NTM disease show tremendous geographic variation in prevalence and mycobacterial species $(7,8)$, suggesting the possibility of differences for extrapulmonary NTM as well, given the environmental influences on NTM disease dynamics. To characterize the epidemiology of skin and soft tissue (SST) and disseminated NTM infections and evaluate regional differences in incidence and mycobacterial species distribution, we examined laboratory-confirmed cases from a large electronic health record (EHR)-based repository of inpatient encounters from a national sample of US hospitals.

${ }^{1}$ Current affiliation: Centers for Disease Control and Prevention, Atlanta, Georgia, USA. 


\section{Methods}

The nationally distributed, hospital-based Cerner Health Facts EHR database (https://sc-ctsi.org/resources/cerner-health-facts) includes linked demographic, clinical, and microbiological information for $\approx 9$ million US inpatients. Using this database, we identified all US patients hospitalized during 2009-2014 with positive NTM cultures from extrapulmonary sources (excluding $M$. gordonae because it is considered an environmental contaminant) (Appendix Table 1, https://wwwnc.cdc.gov/EID/ article/27/3/20-1087-App1.pdf). Patients were classified as having SST disease, disseminated disease (including those with infections in blood, central nervous system, and sterile bone and joint sources), or both; patients with infections from abdominal sites, urinary system, or other body sites were also identified and grouped as other sources (Table 1; Appendix Tables 2,3). Sources were further classified as sterile or not sterile and whether they were associated with a device, prosthesis, or surgical procedure (Table 2). We excluded from analysis 142 patients with isolates from unknown sources and 4,385 patients with isolates from pulmonary sources.

Patients with extrapulmonary NTM were described by demographic factors (age, sex, race, and

\begin{tabular}{|c|c|}
\hline Infection type & Site \\
\hline Skin and soft tissue & $\begin{array}{l}\text { Arm, boil, cheek, ear, foot, genital, } \\
\text { groin, incision, leg, lymph node, } \\
\text { mass, neck, node, nodule, skin, } \\
\text { thigh, tissue, wound }\end{array}$ \\
\hline \multicolumn{2}{|l|}{ Disseminated } \\
\hline Blood & $\begin{array}{c}\text { Blood, blood capillary, blood line, } \\
\text { blood venous, blood whole, central } \\
\text { line }\end{array}$ \\
\hline Bone and joint (sterile) & $\begin{array}{l}\text { Bone, bone marrow, wrist, synovial } \\
\text { fluid, jaw, joint fluid, knee, hip }\end{array}$ \\
\hline Central nervous system & Cerebrospinal fluid \\
\hline \multicolumn{2}{|l|}{ Other } \\
\hline Abdominal & $\begin{array}{l}\text { Liver, ascites fluid, gastric tube, } \\
\text { abdominal fluid, gastric fluid, } \\
\text { nasogastric aspirate, peritoneal, } \\
\text { peritoneal dialysis fluid, peritoneal } \\
\text { fluid, gastric aspirate, perianal, } \\
\text { colonic wash, feces, rectal, } \\
\text { percutaneous endoscopic } \\
\text { gastrostomy site }\end{array}$ \\
\hline Urinary & $\begin{array}{c}\text { Urine, urine catheterized, urine } \\
\text { clean catch, urine midstream, urine } \\
\text { voided }\end{array}$ \\
\hline Other & $\begin{array}{l}\text { Eye fluid, cervical, pericardial fluid, } \\
\text { sternal, exit site, foreign body, } \\
\text { pacemaker, plate, prosthesis, } \\
\text { surgical, nasopharynx, throat, } \\
\text { nonsterile bone and joint }\end{array}$ \\
\hline
\end{tabular}

${ }^{*}$ Data from in Cerner Health Facts database (https://sc-

ctsi.org/resources/cerner-health-facts). geographic region) and clinical factors (underlying conditions and procedural history via codes from the International Classification of Diseases, Ninth and Tenth Revisions, and Current Procedural Terminology). To compare demographics by infection type, we used the Pearson $\chi^{2}$ test or analysis of variance, where appropriate. We calculated overall and annual inpatient prevalence estimates by determining the number of unique inpatients with $\geq 1$ positive extrapulmonary NTM culture divided by the total number of unique inpatients identified during the study period among hospitals reporting $\geq 1$ case of extrapulmonary NTM. Patients whose cultures grew multiple NTM species or had isolates cultured from multiple extrapulmonary sites were counted in each group unless specified. Statistical analyses were conducted by using $\mathrm{R}$ version 4.0 .2 (https://www.R-project.org).

\section{Results}

Of 9,196,147 unique inpatients from 275 inpatient facilities reporting culture results throughout the United States, laboratory-confirmed extrapulmonary NTM was reported for 998 unique species/ source isolates from 831 patients at 89 hospitals. Isolates represented 321 (39\%) patients with SST infections, 269 (32\%) with disseminated infections, and 337 (41\%) with infection at other sites. Both disseminated and SST infections were reported for 23 (2.8\%) patients. Most isolates identified to the species level were Mycobacterium avium complex (MAC) (50\%), followed by M. fortuitum (10\%), M. abscessus (9.4\%), M. chelonae (5.3\%), and M. chelonae/abscessus (4.3\%). Other species were rapidly growing NTM $(8.7 \%)$, non-rapidly growing NTM $(3.7 \%)$, or not speciated (7.9\%) (Table 3).

The overall 6-year prevalence of extrapulmonary NTM in hospitals reporting $\geq 1$ inpatient with extrapulmonary NTM was 11 cases/100,000 inpatients. Site-specific infections were 4.4 SST infections $/ 100,000$ inpatients, 3.7 disseminated infections $/ 100,000$ inpatients, and 0.3 cases of both types of infection/100,000 inpatients. Annual prevalence of disseminated NTM remained stable over the study period, whereas SST infections increased 8.2\% (95\% CI 1\%-15\%) (Figure 1). Prevalence was highest in the Midwest (13 cases /100,000 inpatients), South (13 cases $/ 100,000$ inpatients), and Northeast (11 cases/100,000 inpatients) and lowest in the West (5.3 cases/100,000 inpatients).

Among patients, $49 \%$ were female, $58 \%$ were White, and $60 \%$ were $>40$ years of age; $32 \%$ were Black and $11 \%$ were $<18$ years of age. Relative to patients with SST infections, those with 
Table 2. Sources of extrapulmonary nontuberculous mycobacterial infection, by site sterility and association with medical device, prosthetics, and surgery, United States, 2009-2014*

\begin{tabular}{|c|c|c|c|c|}
\hline Source & Sterile, no. (\%) & $\begin{array}{l}\text { Not sterile, } \\
\text { no. }(\%)\end{array}$ & $\begin{array}{l}\text { Device/prosthesis } \\
\text { associated, no. (\%) }\end{array}$ & $\begin{array}{c}\text { Surgery-associated, } \\
\text { no. }(\%)\end{array}$ \\
\hline Skin and soft tissue, $n=340$ & $33(10)$ & $307(90)$ & $59(17)$ & $129(38)$ \\
\hline \multicolumn{5}{|l|}{ Disseminated, $\mathrm{n}=290$} \\
\hline Blood, $n=259$ & $259(100)$ & NA & $72(28)$ & $26(10)$ \\
\hline Bone and joint, $n=26$ & $26(100)$ & NA & $7(27)$ & $7(27)$ \\
\hline Central nervous system, $n=5$ & $5(100)$ & NA & $3(60)$ & $3(60)$ \\
\hline \multicolumn{5}{|l|}{ Other, $n=362$} \\
\hline Abdominal, $n=110$ & $21(19)$ & $89(81)$ & $27(24)$ & $17(15)$ \\
\hline Urinary, $n=11$ & 0 & $11(100)$ & $2(18)$ & $1(9)$ \\
\hline Other, $n=241$ & $64(27)$ & $177(73)$ & $49(20)$ & $87(36)$ \\
\hline
\end{tabular}

disseminated cases were more frequently male $(60 \%$ vs. $45 \%$; $\mathrm{p}<0.001$ ), younger (mean age 40 vs. 50 years; p<0.001), and Black (56\% vs. $13 \%$; p<0.001). Among patients with both SST and disseminated infection, $61 \%$ were female, most (52\%) were White, and mean age was 52 years (Table 4). Among patients with SST infections, $15 \%$ had undergone a surgical procedure (e.g., invasive, minimally invasive, surgical biopsy) compared with $4 \%$ of patients with disseminated infection. Among all patients, $20 \%$ had ever taken an immunosuppressive drug (Table 4); among these, $19 \%$ had SST infection, $23 \%$ had disseminated infection, and $22 \%$ had both. Crude overall mortality rate was 5\% (11\% among those with disseminated and $2 \%$ among those with SST infections); 1 patient with both types of infection died.

MAC accounted for more than half of disseminated (54\%) and SST infections (52\%), and rapidly growing NTM accounted for $34 \%$ of SST infections and $37 \%$ of disseminated infections. Distribution of cases by source and species varied by region (Table 4). SST infections were more common in the Midwest ( $30 \%$ vs. $18 \%$; $\mathrm{p}=0.002)$ and Northeast $(32 \%$ vs. $18 \% ; \mathrm{p}<0.001)$, and disseminated infections were more common in the South $(60 \%$ vs. $32 \%$; $\mathrm{p}<0.001)$. MAC was found at a higher proportion than rapidly growing NTM in the Northeast (30\% vs. $13 \%$; $<<0.001$ ), and rapidly growing NTM were found at a higher proportion in the Midwest (32\% vs. $23 \%$; $p=0.004)$ and South (52\% vs .40\%; $p=0.001)$. When infections were broken down further by species and infection type, a significantly higher proportion of MAC was found in the Northeast for disseminated $(62 \%$ vs. $29 \% ; p=0.002)$ and SST infections $(72 \%$ vs. $12 \%$; $<<0.001)$ and in the South for disseminated infections $(54 \%$ vs. $36 \%$; $<<0.001)$. Compared with MAC, the proportion of rapidly growing NTM causing SST infections was higher in the South $(51 \%$ vs. $33 \%$; $p=0.009$ ) (Figure 2).

Underlying conditions included fungal coinfections (11\%), HIV infection (13\%), cancer $(4 \%)$, and other immunodeficiencies (2\%); 14 (2\%) NTM patients had a history of invasive cardiac procedures (Table 4). A higher proportion of patients with MAC than with rapidly growing NTM had HIV infection $(21 \%$ vs. $1.5 \%$; $p<0.001)$ and fungal infections ( $16 \%$ vs. $6.7 \%$; $p<0.001)$, and a higher proportion of patients with rapidly growing NTM had cancer (6.7\% vs. $1.4 \%$; p<0.001). Coinfections (including pulmonary pathogens) identified during the same hospitalization as NTM isolation were common; $\geq 1$ concomitant pathogen of interest grew for $42 \%$ of patients (Appendix Table 4 ).

By extrapulmonary NTM infection type, coinfection was found for $37 \%$ of patients with SST, $47 \%$ with disseminated, and $61 \%$ with both. Among all persons with co-infection, $13 \%$ had Staphylococcus spp., $10 \%$ had Candida spp., $9.0 \%$ had Enterococcus spp., $7.0 \%$ had Streptococcus spp., $6.6 \%$ had Pseudomonas

\begin{tabular}{|c|c|c|c|c|}
\hline Species & Total no. (\%) & Disseminated, no. (\%) & $\begin{array}{c}\text { Skin and soft tissue, } \\
\text { no. }(\%)\end{array}$ & Other, no. (\%) \\
\hline Mycobacterium avium complex & $501(50)$ & $157(54)$ & $177(52)$ & $167(45)$ \\
\hline M. abscessus & $94(9)$ & $24(8)$ & $27(8)$ & $43(12)$ \\
\hline M. abscessus/chelonae & $43(4)$ & $13(4)$ & $15(4)$ & $15(4)$ \\
\hline M. chelonae & $53(5)$ & $14(5)$ & $21(6)$ & $18(5)$ \\
\hline M. fortuitum & $104(10)$ & $20(7)$ & $36(11)$ & $48(13)$ \\
\hline M. kansasii & $26(3)$ & $6(2)$ & $9(3)$ & $11(3)$ \\
\hline Mycobacterium spp. & $79(8)$ & $17(6)$ & $20(6)$ & $42(11)$ \\
\hline Other non-rapidly growing NTM & $37(4)$ & $3(1)$ & $20(6)$ & $14(4)$ \\
\hline Other rapidly growing NTM & $61(6)$ & $36(12)$ & $15(4)$ & $10(3)$ \\
\hline Total & $998(100)$ & $290(29)$ & $340(34)$ & $368(37)$ \\
\hline
\end{tabular}

*Data from in Cerner Health Facts database (https://sc-ctsi.org/resources/cerner-health-facts). 


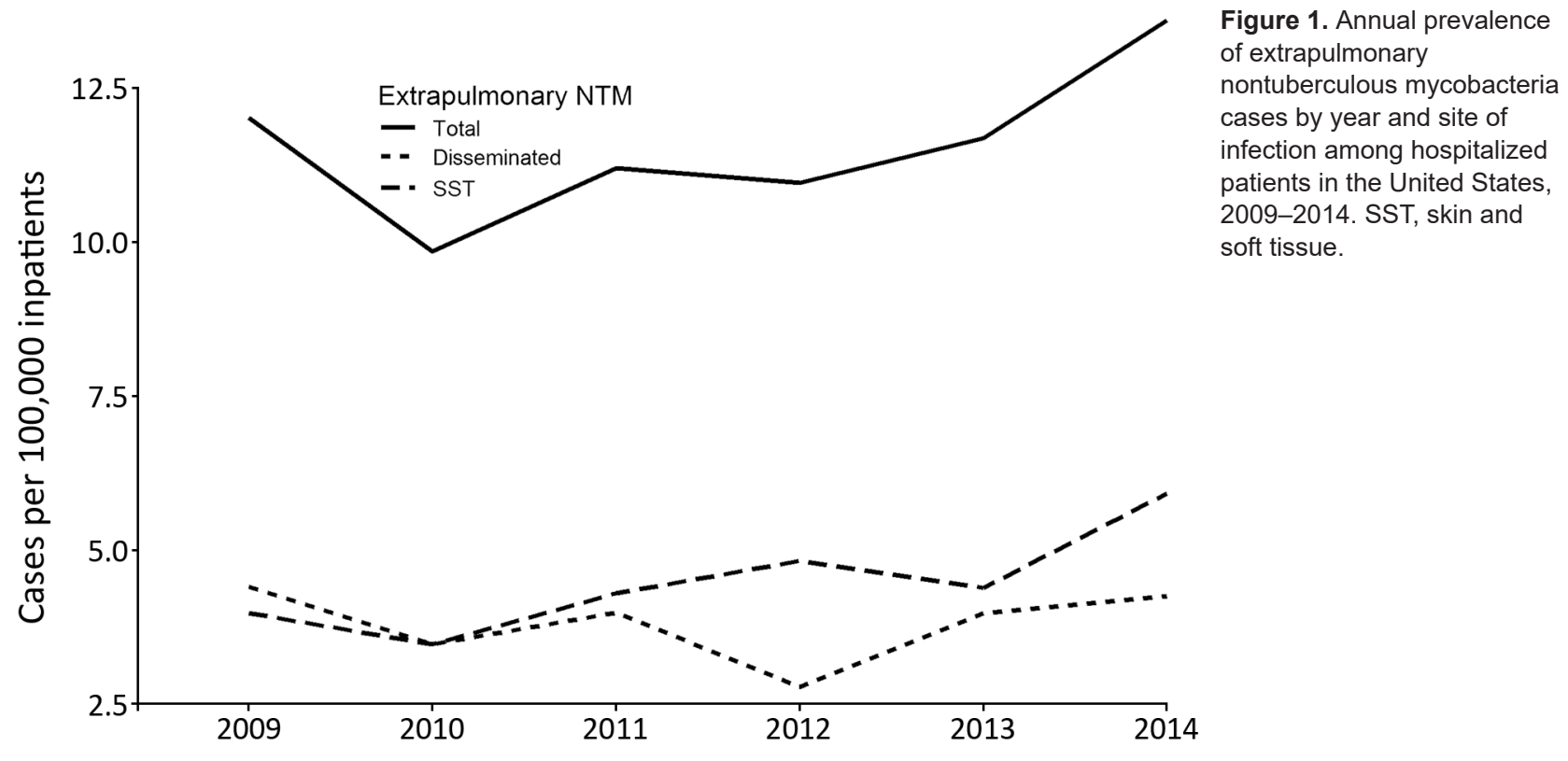

spp., 5.2\% had Escherichia coli, 3.8\% had Klebsiella spp., and $8.2 \%$ had M. tuberculosis complex (MTBC) (Table 5). Of patients with both SST and disseminated NTM, $36 \%$ were co-infected with Enterococcus spp., 26\% with MTBC, and $29 \%$ with Staphylococcus spp. (Figure 3). Patients with disseminated NTM had a higher proportion of Acinetobacter spp., Bacillus spp., Candida spp., Clostridium spp., Coccidioides spp., Cryptococcus spp., Enterococcus spp., E. coli, Stenotrophomonas spp., and Streptococcus spp. infection; patients with SST NTM infection had a higher proportion of Aeromonas spp., Aspergillus spp., Corynebacterium spp., Enterobacter spp., Klebsiella spp., MTBC, Salmonella spp., and Staphylococcus spp., although the differences were not significant (Table 5; Figure 3).

\section{Discussion}

Using the Cerner Health Facts EHR database, we found that the annual prevalence of extrapulmonary NTM overall was stable over time and that SST NTM infections increased significantly, which could result from the increased number of patients taking immunosuppressive drugs ( $20 \%$ of patients in this cohort) or increased cosmetic procedures (e.g., tattooing, pedicures) $(10,11)$. Although population-based studies have found a lower and stable prevalence of extrapulmonary NTM, it is possible that the higher prevalence we found results from patients having more severe infections that necessitate testing, increasing the chances of diagnosing this disease $(4,11)$.

NTM infections varied by geographic region in prevalence, infection type, and mycobacterial species. Specifically, prevalence of extrapulmonary
NTM was higher among hospitalized patients in the South, Midwest, and Northeast than in the West, although these high rates resulted from disseminated infection in the South versus a more even distribution of SST infections in other regions. Recent studies of extrapulmonary NTM in the United States have focused on specific geographic locations. In Oregon, Shih et al. (12) and Henkle et al. (4) analyzed all extrapulmonary NTM cases identified via statewide laboratory-based active surveillance efforts and estimated incidence rates to be 1.1-1.5 cases/100,000 persons/year, with only one third of those patients hospitalized (12). These estimates are substantially lower than those reported in North Carolina (13), where a similar surveillance-based study estimated the prevalence among residents of 3 counties to be $\approx 3$ cases $/ 100,000$ persons. The differences in prevalence estimates between Oregon and North Carolina similarly reflect the regional differences that we observed; prevalence was higher in southern than in western states. The geographic variations in prevalence of extrapulmonary NTM cases that we found are also similar to what has been shown in US populationlevel pulmonary NTM studies $(8,14,15)$, that residents of southern states are at increased risk for NTM lung disease, particularly among highrisk groups such as persons with cystic fibrosis (15-17). Differences by geographic region are largely associated with environmental factors, such as greater amounts of water on land and in the lower level atmosphere (14-16), which probably contributes to increased environmental abundance 
Table 4. Demographic and clinical characteristics of extrapulmonary nontuberculous mycobacteria cases among hospitalized patients from 82 hospitals, United States, 2009-2014*

\begin{tabular}{|c|c|c|c|c|c|}
\hline Characteristics & $\begin{array}{c}\text { Extrapulmonary NTM, } \\
\text { no. }(\%), n=831\end{array}$ & $\begin{array}{l}\text { Disseminated, no. } \\
(\%), n=246\end{array}$ & $\begin{array}{l}\text { SST, no. }(\%) \\
n=298\end{array}$ & $\begin{array}{l}\text { Other, no. (\%), } \\
\quad n=264\end{array}$ & $\begin{array}{c}\text { Both, no. (\%), } \\
n=23\end{array}$ \\
\hline \multicolumn{6}{|l|}{ Patient characteristic } \\
\hline \multicolumn{6}{|l|}{ Sex } \\
\hline $\mathrm{F}$ & 409 (49) & $98(40)$ & $164(55)$ & $133(50)$ & $14(61)$ \\
\hline M & $422(51)$ & $148(60)$ & $134(45)$ & $131(50)$ & $9(39)$ \\
\hline \multicolumn{6}{|l|}{ Race/ethnicity } \\
\hline White & $478(58)$ & $93(38)$ & $228(77)$ & $145(55)$ & $12(52)$ \\
\hline Black & $269(32)$ & $138(56)$ & $38(13)$ & $83(31)$ & $10(43)$ \\
\hline Other & $84(10)$ & $15(6)$ & $32(11)$ & $36(14)$ & $1(4)$ \\
\hline \multicolumn{6}{|l|}{ Age group, y } \\
\hline$\leq 18$ & $91(11)$ & $13(5)$ & $43(14)$ & 35 (13) & 0 \\
\hline$>18-40$ & 244 (29) & $121(49)$ & 47 (16) & $70(27)$ & $6(26)$ \\
\hline$>40-60$ & $266(32)$ & $86(35)$ & $93(31)$ & $78(30)$ & $9(39)$ \\
\hline$>60$ & $230(28)$ & $26(11)$ & $115(39)$ & $81(31)$ & $8(35)$ \\
\hline \multicolumn{6}{|l|}{ Ever had } \\
\hline Fungal Infection & $92(11)$ & $53(22)$ & $13(4)$ & $22(8)$ & $4(17)$ \\
\hline HIV infection & $104(13)$ & $63(26)$ & $9(3)$ & $26(10)$ & $6(26)$ \\
\hline Invasive cardiac procedure & $18(2)$ & $4(2)$ & $6(2)$ & $7(3)$ & $1(4)$ \\
\hline Cancer & $31(4)$ & $11(4)$ & $9(3)$ & $11(4)$ & 0 \\
\hline Other immunologic disorder† & $18(2)$ & $8(3)$ & $3(1)$ & $7(3)$ & 0 \\
\hline $\begin{array}{l}\text { In-hospital death or discharged } \\
\text { to hospice }\end{array}$ & $47(6)$ & $29(12)$ & $5(2)$ & $12(5)$ & $1(4)$ \\
\hline \multicolumn{6}{|l|}{ Hospital characteristic } \\
\hline \multicolumn{6}{|l|}{ Region } \\
\hline South & $375(45)$ & $147(60)$ & $94(32)$ & $125(47)$ & $9(39)$ \\
\hline Northeast & $202(24)$ & $44(18)$ & $95(32)$ & $56(21)$ & $7(30)$ \\
\hline Midwest & $200(24)$ & $44(18)$ & $88(30)$ & $64(24)$ & $4(17)$ \\
\hline West & $54(6)$ & $11(4)$ & $21(7)$ & $19(7)$ & $3(13)$ \\
\hline \multicolumn{6}{|l|}{ Setting } \\
\hline Urban & $764(92)$ & $231(94)$ & $278(93)$ & $234(89)$ & $21(91)$ \\
\hline Rural & $67(8)$ & $15(6)$ & $20(7)$ & $30(11)$ & $2(9)$ \\
\hline \multicolumn{6}{|l|}{ Teaching status $\ddagger$} \\
\hline Teaching facility & $686(83)$ & $210(85)$ & $247(83)$ & $209(79)$ & $20(87)$ \\
\hline Not teaching facility & $112(13)$ & $30(12)$ & $35(12)$ & 209 (17) & $3(13)$ \\
\hline \multicolumn{6}{|c|}{$\begin{array}{l}\text { *Data from in Cerner Health Facts database (https://sc-ctsi.org/resources/cerner-health-facts). Both, disseminated and SST infection; SST, skin and soft } \\
\text { tissue. } \\
\text { †Antineoplastic and immunosuppressive drugs causing adverse effects in therapeutic use, autoimmune disease, not elsewhere classified, common } \\
\text { variable immunodeficiency, encounter for antineoplastic immunotherapy, immunodeficiency with predominant T-cell defect, unspecified, other and } \\
\text { unspecified nonspecific immunological findings, other specified disorders involving the immune mechanism, personal history of immunosuppression } \\
\text { therapy, unspecified disorder of immune mechanism, unspecified immunity deficiency. } \\
\ddagger \text { Status unknown for } 33 \text { patients. }\end{array}$} \\
\hline
\end{tabular}

of mycobacteria. In addition to higher levels of exposure to mycobacteria, studies have identified that these high-risk areas also tend to have a higher proportion of rapidly growing NTM species relative to MAC or other mycobacteria $(7,15,17)$, which can result in more severe disease with limited effective treatment options (3).

Among extrapulmonary NTM cases, mycobacteria species also varied greatly by infection source and underlying condition. Although MAC infections were most frequent across all types of extrapulmonary NTM cases, in certain regions rapidly growing NTM play a substantial role in causing disease. Nearly all patients with HIV had MAC; those with a history of cancer were more likely to have rapidly growing NTM. Given that species of rapidly growing NTM, particularly $M$. abscessus and M. fortuitum, which were the most prevalent species in this study, are typically more challenging to treat than MAC, these findings have implications for the clinical management of these patients with complex infections and medical conditions. Co-infections were common among patients with extrapulmonary NTM, and $\geq 1$ other pathogen was isolated from nearly half of all patients. Co-infections may complicate treatmentrelated decisions, particularly if mycobacteria, which are typically slow growing, are detected after other pathogens and are not treated with appropriate antimicrobial drug therapy.

Because we evaluated $\approx 9$ million unique persons from 275 hospitals across the United States, we were able to identify key epidemiologic patterns for what is otherwise a very rare disease with limited populationlevel data. Because our analysis included only hospitalized patients, we probably overestimated the true incidence of extrapulmonary NTM disease 
Table 5. Concomitant organisms isolated from hospitalized patients with extrapulmonary nontuberculous mycobacteria, overall and by source, United States, 2009-2014*

\begin{tabular}{|c|c|c|c|c|c|}
\hline Genus & Total, no. (\%) & Disseminated, no. (\%) & SST, no. (\%) & Both, no. (\%) & Other, no. (\%) \\
\hline Acinetobacter & $9(3)$ & $5(5)$ & $2(2)$ & 0 & $2(2)$ \\
\hline Aeromonas & $3(0.9)$ & 0 & $1(1)$ & 0 & $2(2)$ \\
\hline Aspergillus & $7(2)$ & $2(2)$ & $3(3)$ & 0 & $2(2)$ \\
\hline Bacillus & $15(4)$ & $5(5)$ & $5(5)$ & $1(7)$ & $4(3)$ \\
\hline Candida & $80(23)$ & $26(25)$ & $22(20)$ & $1(7)$ & $31(26)$ \\
\hline Clostridium & $9(3)$ & $4(4)$ & $2(2)$ & 0 & $3(3)$ \\
\hline Coccidioides & $2(0.6)$ & $1(1)$ & 0 & 0 & $1(1)$ \\
\hline Corynebacterium & $31(9)$ & $8(8)$ & $13(12)$ & 0 & $10(8)$ \\
\hline Cryptococcus & $6(2)$ & $4(4)$ & $1(1)$ & 0 & $1(1)$ \\
\hline Enterobacter & $13(4)$ & 1 (1) & $6(5)$ & 0 & $6(5)$ \\
\hline Enterococcus & $75(21)$ & $27(26)$ & $25(23)$ & $5(36)$ & $18(15)$ \\
\hline Escherichia coli & $43(12)$ & $11(11)$ & $11(10)$ & $1(7)$ & $20(17)$ \\
\hline Klebsiella & $32(9)$ & $5(5)$ & $13(12)$ & $1(7)$ & $13(11)$ \\
\hline Mycobacterium tuberculosis & $68(19)$ & $16(15)$ & $18(16)$ & $5(36)$ & $29(24)$ \\
\hline Pseudomonas & $55(16)$ & $16(15)$ & $17(15)$ & 0 & $22(18)$ \\
\hline Salmonella & $2(0.6)$ & 0 & $1(1)$ & 0 & $1(1)$ \\
\hline Staphylococcus & $112(32)$ & $35(33)$ & $44(40)$ & $4(29)$ & $29(24)$ \\
\hline Stenotrophomonas & $11(3)$ & $4(4)$ & $3(3)$ & $1(7)$ & $3(3)$ \\
\hline Streptococcus & $58(17)$ & $21(20)$ & $13(12)$ & 0 & $24(20)$ \\
\hline Total patients with co-infection & 350 & $105(30)$ & $111(32)$ & $14(4)$ & $120(34)$ \\
\hline
\end{tabular}

in the general population by selecting for generally sicker patients with more severe underlying disease. We may have missed less severe SST infections that did not require extensive treatment or hospital intervention. Because the hospitals included here represent only those that use the Cerner Health Facts system, this study does not include patients at other facilities, which may also affect our incidence calculations. Similarly, not captured here were surgeries, procedures, or prior medical events that occurred in other facilities, which may be associated with risk, infection type, and outcome. However, these limitations would be applied systematically to the entire study population and therefore would probably not alter the geographic or temporal patterns that we found.

Overall, extrapulmonary NTM disease remains rare with relatively stable incidence rates for disseminated NTM infections and modestly increased rates for SST infections. In similar studies assessing pulmonary NTM, rates appear to be steadily increasing in the general population and among high-risk groups such as persons with cystic fibrosis $(8,17)$. Patients with extrapulmonary NTM

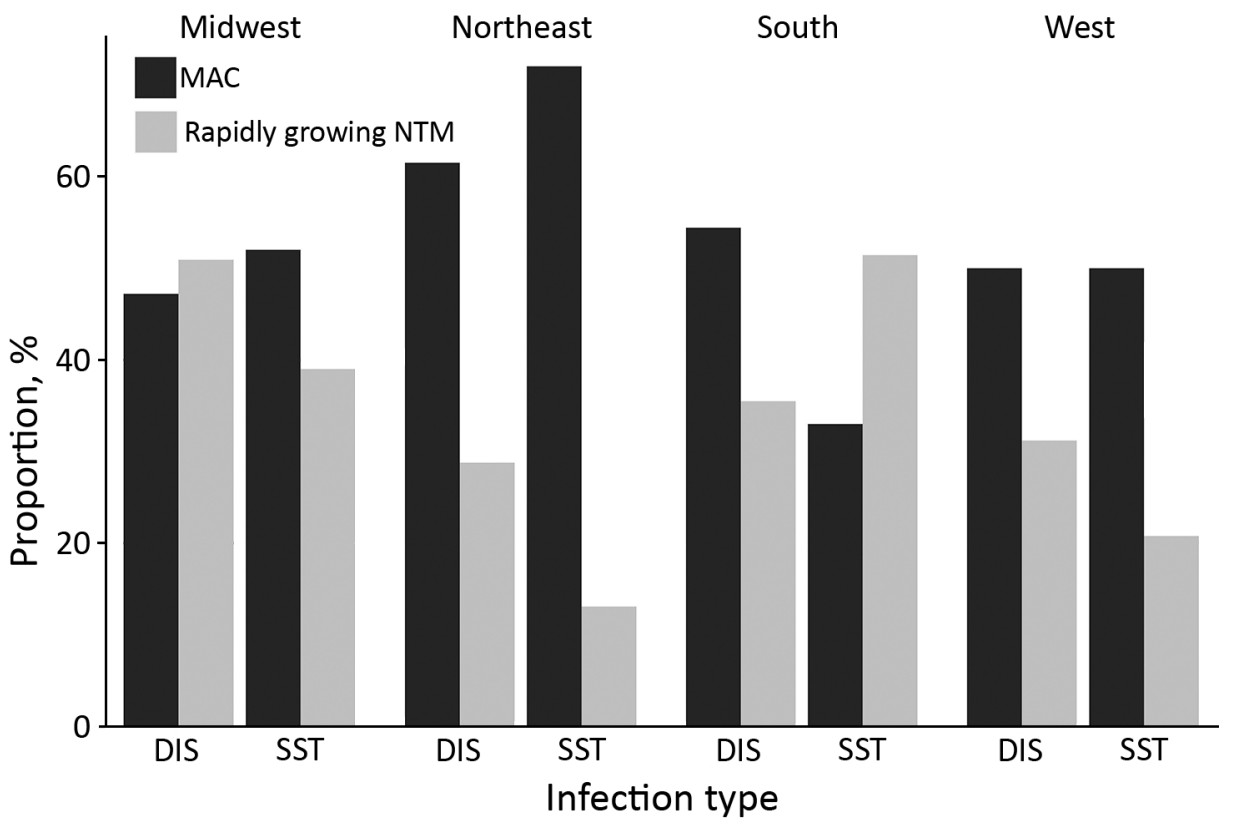

Figure 2. Distribution of extrapulmonary NTM cases by species and infection type across regions among hospitalized patients in the United States, 20092014. DIS, disseminated; NTM, nontuberculous mycobacteria; MAC, Mycobacterium avium complex; SST, skin and soft tissue. 


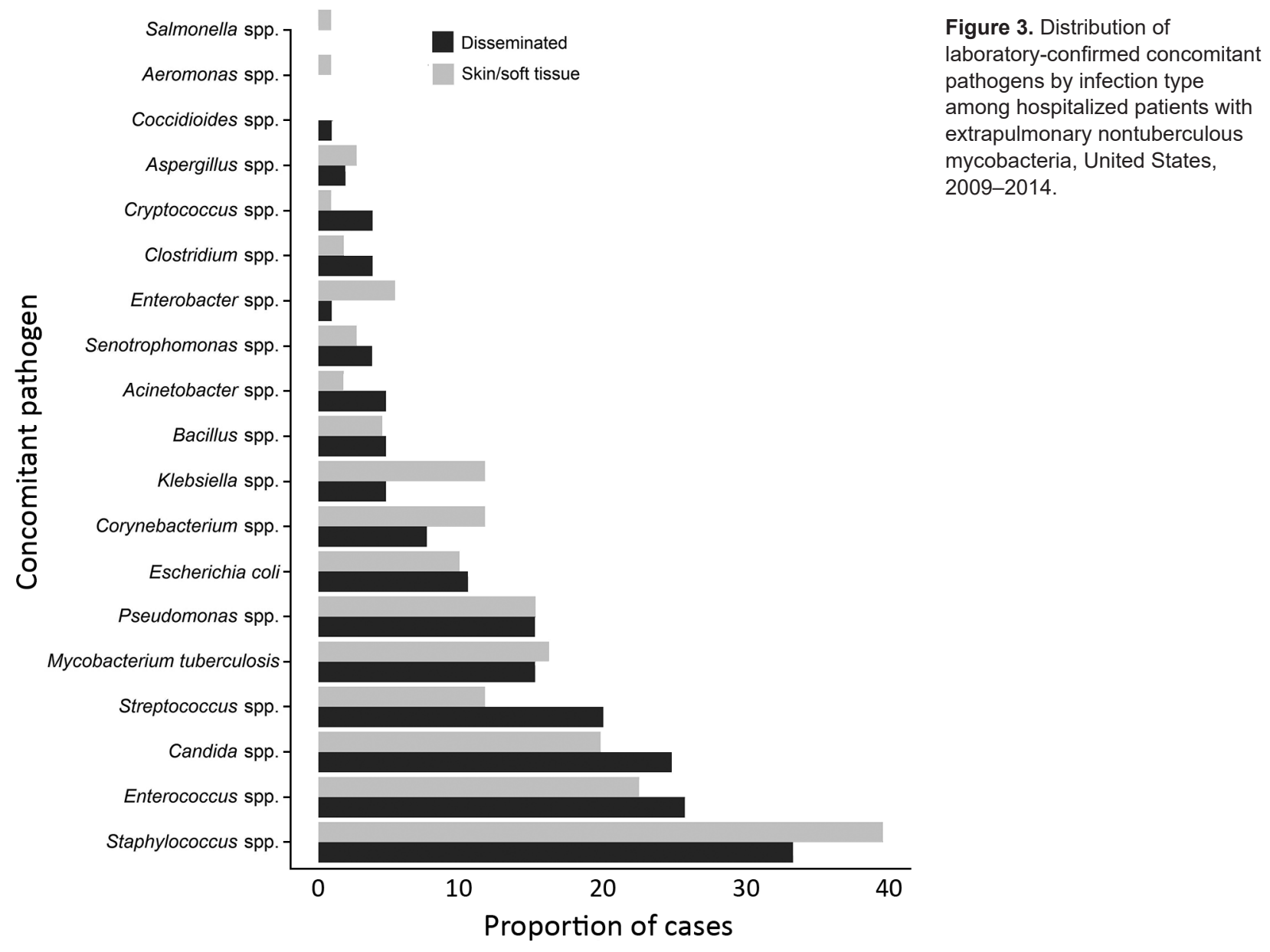

typically include persons with HIV, other underlying immunodeficiencies, histories of surgical procedures, or other unique exposures that increase the risk for infection. In addition, we found that species variability is associated with geographic region; rapidly growing NTM are more prevalent in the southern United States than in other regions. Given the added treatment challenges that exist for these patients with often-complex conditions, knowledge of key trends and risks by patient-level factors and geographic location is critical for improving clinical outcomes and determining sources of infections that may be common to patients with pulmonary and extrapulmonary NTM.

This work was supported by the Division of Intramural Research, National Institute of Allergy and Infectious Diseases, National Institutes of Health.

\section{About the Author}

Dr. Ricotta is a research fellow in the Epidemiology Unit, Division of Intramural Research, National Institute of Allergy and Infectious Diseases, National Institutes of Health. Her research focuses on studying the epidemiology of rare infectious diseases.

\section{References}

1. Falkinham JO III. Nontuberculous mycobacteria in the environment. Clin Chest Med. 2002;23:529-51. https:/ / doi.org/ 10.1016/S0272-5231(02)00014-X

2. Falkinham JO III. Nontuberculous mycobacteria from household plumbing of patients with nontuberculous mycobacteria disease. Emerg Infect Dis. 2011;17:419-24. https://doi.org/10.3201/eid1703.101510

3. Griffith DE, Aksamit T, Brown-Elliott BA, Catanzaro A, Daley C, Gordin F, et al.; ATS Mycobacterial Diseases Subcommittee; American Thoracic Society; Infectious Disease Society of America. An official ATS/IDSA statement: diagnosis, treatment, and prevention of nontuberculous mycobacterial diseases. Am J Respir Crit Care Med. 2007;175:367-416. https://doi.org/10.1164/rccm.200604571ST

4. Henkle E, Hedberg K, Schafer SD, Winthrop KL. Surveillance of extrapulmonary nontuberculous mycobacteria infections, Oregon, USA, 2007-2012. Emerg Infect Dis. 2017;23:1627-30. https:// doi.org/10.3201/eid2310.170845

5. Piersimoni C, Scarparo C. Extrapulmonary infections associated with nontuberculous mycobacteria in 
immunocompetent persons. Emerg Infect Dis. 2009;15:13518. https://doi.org/10.3201/eid1509.081259

6. Lyman MM, Grigg C, Kinsey CB, Keckler MS, Moulton-Meissner $\mathrm{H}$, Cooper E, et al. Invasive nontuberculous mycobacterial infections among cardiothoracic surgical patients exposed to heater-cooler devices. Emerg Infect Dis. 2017;23:796-805. https:/ / doi.org/ 10.3201/eid2305.161899

7. Spaulding AB, Lai YL, Zelazny AM, Olivier KN, Kadri SS, Prevots DR, et al. Geographic distribution of nontuberculous mycobacterial species identified among clinical isolates in the United States, 2009-2013. Ann Am Thorac Soc. 2017;14:165561. https:// doi.org/10.1513/AnnalsATS.201611-860OC

8. Adjemian J, Olivier KN, Seitz A, Holland S, Prevots R. Prevalence of pulmonary nontuberculous mycobacterial infections among U.S. Medicare beneficiaries, 1997-2007. Am J Respir Crit Care Med. 2012;85:881-6.

10. Wi YM. Treatment of extrapulmonary nontuberculous mycobacterial diseases. Infect Chemother. 2019;51:245-55. https://doi.org/10.3947/ic.2019.51.3.245

11. Wentworth AB, Drage LA, Wengenack NL, Wilson JW, Lohse CM. Increased incidence of cutaneous nontuberculous mycobacterial infection, 1980 to 2009: a population-based study. Mayo Clin Proc. 2013;88:38-45. https:/ / doi.org/ 10.1016/j.mayocp.2012.06.029

12. Shih DC, Cassidy PM, Perkins KM, Crist MB, Cieslak PR Leman RL. Extrapulmonary nontuberculous mycobacterial disease surveillance-Oregon, 2014-2016. MMWR Morb Mortal Wkly Rep. 2018;67:854-7. https://doi.org/10.15585/ mmwr.mm6731a3
13. Smith GS, Ghio AJ, Stout JE, Messier KP, Hudgens EE, Murphy MS, et al. Epidemiology of nontuberculous mycobacteria isolations among central North Carolina residents, 2006-2010. J Infect. 2016;72:678-86. https://doi.org/10.1016/j.jinf.2016.03.008

14. Adjemian J, Olivier KN, Seitz AE, Falkinham JO III, Holland SM, Prevots DR. Spatial clusters of nontuberculous mycobacterial lung disease in the United States. Am J Respir Crit Care Med. 2012;186:553-8. https:/ / doi.org/10.1164/ rccm.201205-0913OC

15. Adjemian J, Olivier K, Prevots DR. Nontuberculous mycobacteria among cystic fibrosis patients in the United States: screening practices and environmental risk. Am J Respir Crit Care Med. 2014;190:581-6. https://doi.org/ 10.1164/rccm.201405-0884OC

16. Bouso JM, Burns JJ, Amin R, Livingston FR, Elidemir O. Household proximity to water and nontuberculous mycobacteria in children with cystic fibrosis. Pediatr Pulmonol. 2017;52:324-30. https://doi.org/10.1002/ppul.23646

17. Adjemian J, Olivier KN, Prevots DR. Epidemiology of pulmonary nontuberculous mycobacterial sputum positivity in patients with cystic fibrosis in the United States, 2010-2014. Ann Am Thorac Soc. 2018;15:817-26. https:/ / doi.org/10.1513/AnnalsATS.201709-727OC

Address for correspondence: Emily Ricotta, National Institute of Allergy and Infectious Diseases, National Institutes of Health, 5601 Fishers Ln, 7D18, Rockville, MD 20852, USA; email: emily.ricotta@nih.gov

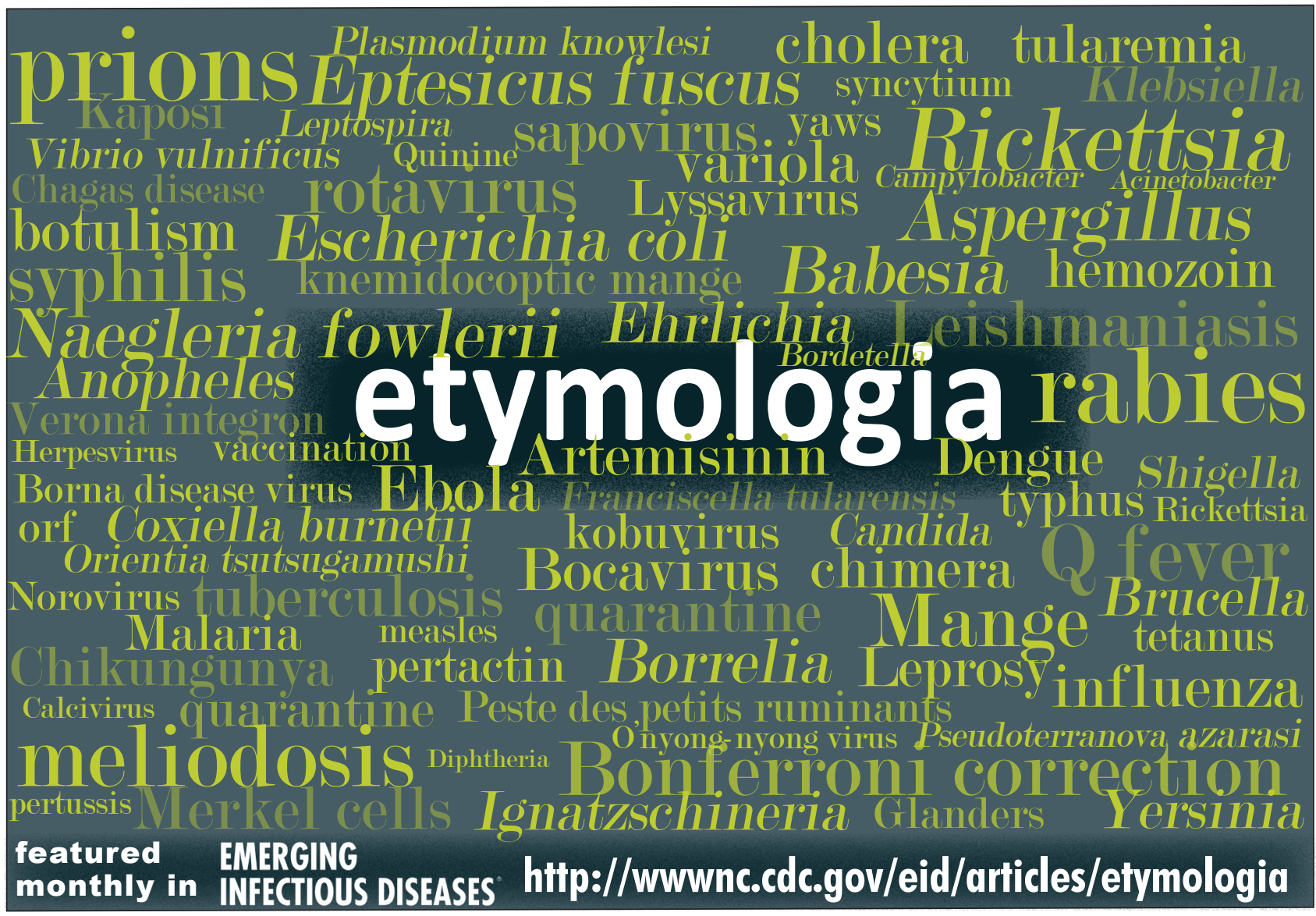

